.

\author{
Fom: CURRENT TRENDS IN HISTOCOMPATIBILITY, Vol 2 \\ Edired by Ralph A. Raisfely and So'da 10 Ferrone \\ (Plenum Publishing Corporation. 1 , di)
}

\title{
The Enigma of Good Kidney-Graft Survival in the Face of Poor HLA Matches
}

\section{HLA Matching for Kidney Transplantation Makes Sense}

\author{
J.J. van Rood, G.G. Persijn, E. Goulmy, and \\ B.A. Bradley
}

\section{Introduction}

One of the few facts all those involved in kidney allografting agreed on almost from the beginning is that matching for the HLA system plays an overriding role when donor and recipient are siblings. It was one of the fundamental observations that identified the HLA system as the major histocompatibility complex (MHC).

Although the HLA system is extremely complex, its polymorphism can be considered finite. This implies that unrelated individuals exist who share one or two HLA haplotypes. In the parent-child combination, matching for the unrelated haplotype was shown to improve kidney-graft survival (van Rood et al., 1967). On the basis of this observation, it was suggested that to overcome the difficulty of finding good matches between unrelated individuals, a large pool of patients awaiting kidney transplantation should be created (van Rood, 1967). Whenever a kidney donor becomes available, the best-matched recipient is selected from the pool.

Although this proposal, which led to unique international and inter-

J J van Rood, E Goulmy, and B A Bradley - Department of Immunohdematology, University Medical Center, Leiden, The Netherlands GG Persın - Eurotransplant Foundation, Unversity Medical Center, Leiden, The Netherlands 
center medical collaboration, was receıved well, it took ten years before the consensus was reached that HLA matching was helpful in the unrelated donor-recipient combinations (Transplantatıon Proceedings, 1977). In retrospect, this delay can be explained by the following considerations

1. Many of the early studies had, because of the extreme polymorphism of $H L A$, far too few "good" matches-1.e., $H L A-A$ - and - $B$ identical matches - to allow for a meaningful interpretation of the data

2. The influence of linkage dysequilibrium was insufficiently taken into account in most studies.

3 In the unrelated donor-recipient combination, where complete $H L A$ identity is rare, if it occurs at all, helper or suppressor mechanısms, or both, can be activated that make a simplistic interpretation of the number of $H L A-A$ and $-B$ mismatches redundant.

That $H L A-A$ and $-B$ matching does improve kıdney allograftıng is illustrated by Fig. 1, which presents the results obtaned in the organexchange organization Eurotransplant in the period 1972-1977 and concerns over 3000 first cadaveric transplants (Persın et al, 1979). The data show that 5 years after transplantation, grafts with no $H L A-A$ and $-B$ mismatches do over $15 \%$ better than grafts mismatched for three or four antigens. The difference is statistically significant from 6 months posttransplant onward and meaningful both for the patient and in the context of the cost-benefit aspects of the treatment of end-stage renal fallure.

Two further points can be deduced from Fig. 1 as well. The first is that about one third of the transplants fall within the first 3-6 months after transplantation, and the second is that although the grafts mismatched for three or four $H L A-A$ and $-B$ antigens do on the average less well tban those that were better matched, some of these three- to fourantigen-mismatched grafts do quite well even after 5 years In other words, even a good $H L A-A$ and $-B$ match is no guarantee of good function, and by contrast, good graft function can occur vis-à-vis a very poor HLA match It is both of great theoretical importance and of great practical importance to understand the mechanism by which these mismatched grafts are able to survive

Recently, several variables have been identrfied that apart from $H L A-A$ and $-B$ matching per se are able to significantly influence kıdney graft survival. We will discuss three of these Blood transfusion and $H L A-D R$ matching have a graft-protecting effect, while incompatibility for $\mathrm{MHC}$-restricted and $\mathrm{MHC}$-nonrestricted non-HLA antigens can impair graft survival. 


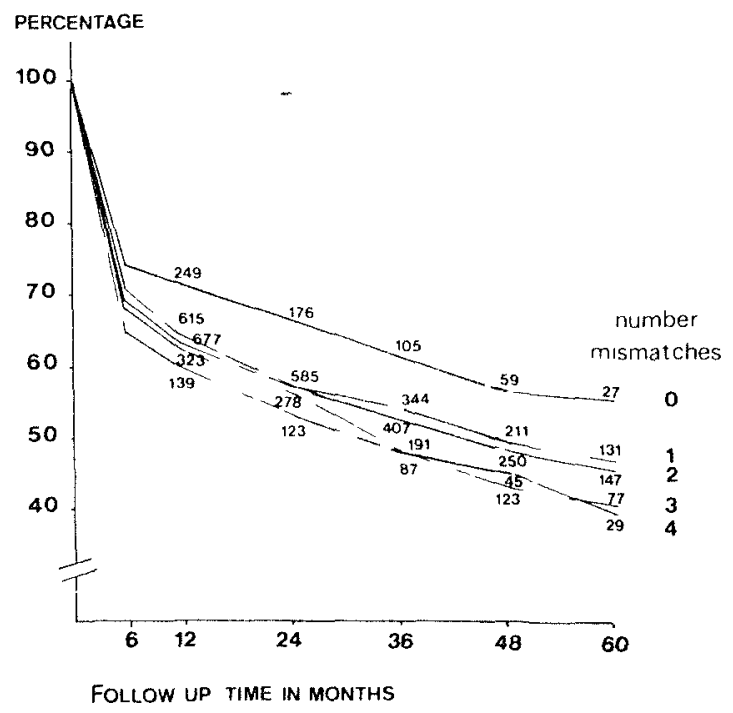

Figure 1. Kidney-graft survival of over 3000 consecutıve transplants performed in collaboration with the Eurotransplant organ-exchange organization. Note that after 6 months, there is an $8 \%$ difference, and after 60 months a 15\% difference, between the best- and poorest-matched grafts. From Persin et al. (1979).

\section{Blood Transfusion}

Opelz et al. (1973) were the first to present significant evidence not only that blood transfusion can cause immunization, which endangers graft survival, but also that it can prolong graft survival. Their observation has been confirmed by most workers, including our own group (Persijn et al., 1977). Furthermore, a randomized prospective study in rhesus monkeys that received five blood transfusions over a 3-month period prior to transplantation and standard immunosuppression after transplantation showed a significant fourfold prolongation of graft survival (Fig. 2) (van Es et al., 1977).

In Leiden, a retrospective study by van Hooff et al. (1976) showed that patients who had received one blood transfusion appeared to do better than patients who had received none. Next, Persijn et al. (1979) evaluated the role of the number of blood transfusions in kidney-graft survival in 895 patients who had received a kidney transplant between January 1, 1967, and March 1, 1977. The transfusion history was checked by scrutinizing the relevant documents (e.g., medical history, blood bank files, hemodialysis reports) and by personal interviews with the patients or therr relatives or both. For female patients, the number of pregnancies 


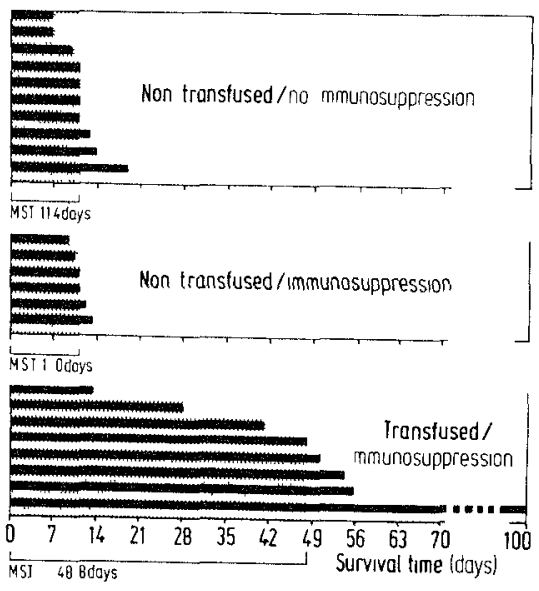

Figure 2 Influence of blood transfusion on kıdney allograft survival in unrelated rhesus monkeys Solid black bars depict individual survival times, shaded areas indicate the mean survival time (M S T) per experimen tal group Immunosuppression consisted of azathıoprine $(4 \mathrm{mg} / \mathrm{kg}$ ) and prednisolone $(2$ $\mathrm{mg} / \mathrm{kg}$ ), given on alternate days Five blood transfusions were given at biweekly inter vals Transplantation was performed 11-23 days after the last transfusion From van Es et al (1977)

and abortıons was recorded. In this way, these authors found 68 male and 6 female patients who had never been transfused or been pregnant before transplantation. None of them had preformed leukocyte antibodies in their serum Similarly, 27 male and 3 never-pregnant female patıents were identified who had received only a single blood transfusion, a third of them 1 year or more before transplantation. Some of these patients remembered the exact date of transfusion, and this was checked and confirmed in the blood bank records. None of these patients had detectable antileukocyte antibodies in their sera. The composition of the transfusate (e.g., whole blood, washed erythrocytes, filtered blood) was not taken into account because accurate information on this was not avallable. All patients in this analysis, except one patient in the nontransfused group, had received blood transfusions during transplantation varying from 1 to more than 5 units. As can be seen in Fig. 3, the patients who had received one blood transfusion did extremely well $(80 \%$ graft survival at 6 months after transplantation), while those who had received no blood transfusion did very poorly indeed.

On the basis of these findings, a prospective trial was started in Holland in which it was planned to compare the graft-protecting effect of one pretransplant transfusion of leukocyte-poor blood with three such transfusions. The precise way in which the blood was to be prepared was not specified. Most centers gave "washed" leukocyte-poor blood, but a few used cotton-wool-filtered blood, which for all practical purposes is leukocyte-free (Diepenhorst et al., 1972) As is shown in Fig. 3, this prospective study confirmed the retrospective study with respect to the graft-protecting effect of one transfusion of leukocyte-poor blood. In contrast, the patients transfused with cotton-wool-filtered leukocyte-free

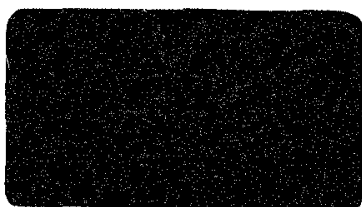




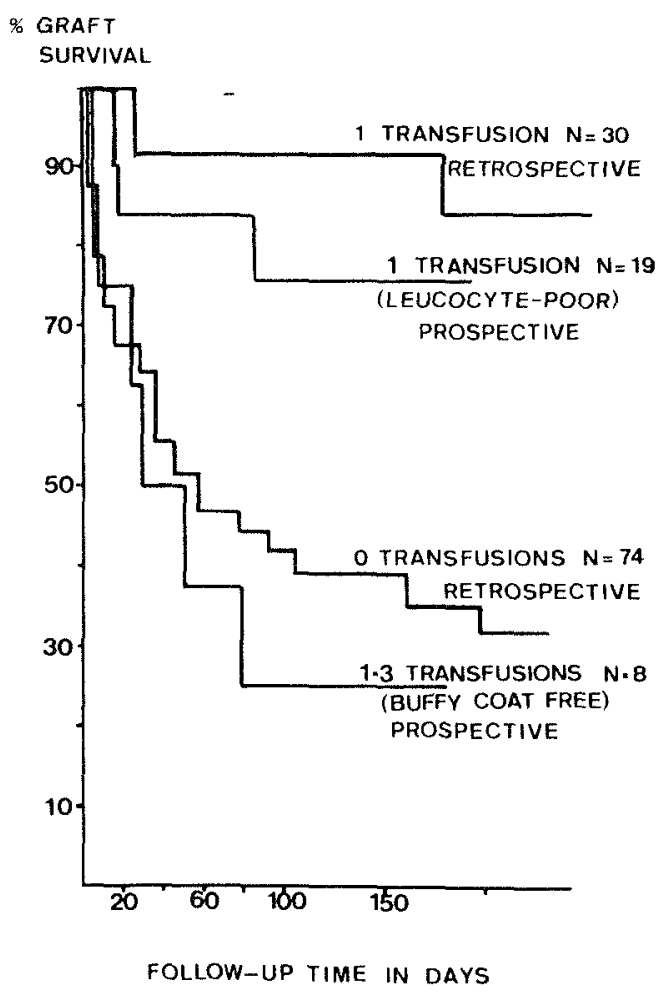

Figure 3. Graft survival in relation to a single pretransplant blood transfusion. Only transfusions of leukocyte-poor blood had a graft-protecting effect. From Persijn et al. (1978).

blood did as poorly as the nontransfused patients. We conclude from these data that a small amount of buffycoat cells given once before transplantation induces significant graft protection and that buffycoatfree erythrocytes will not do so. Others have suggested that peroperative blood transfusions without preoperative ones can cause graft facilitation (Stiller et al., 1978). During the last two years, almost all peroperative blood transfusions to the patients shown in Fig. 3 have been leukocytefree. However, before that date, leukocyte-poor blood was often given. Its effect on graft survival is under study. Because of the very poor overall graft survival in the group of patients who received no blood transfusions before transplantation, it appears unlikely to us that peroperative blood transfusions with leukocyte-poor blood are as effective as preoperative ones.

On two points, our findings are at variance with those of others. 
First, although almost all authors agree that patients who had received pretransplant blood transfusions do better than those who did not, most centers find that graft survival in the nontransfused group is not $20-30 \%$ as we observed (Fig. 3), but 40-60\% at 1 year (Morris et al., 1978; Opelz and Terasaki, 1978). We have no good explanation for this discrepancy. Inadequate inventorying of the blood-transfusion history might be an explanation for some but not for all studies. The poorer graft survival in our nontransfused-patient group is unlikely to be due to poorer $H L A$ matches as compared to the other studies. This discrepancy thus focuses our attention on yet another unknown variable determining the outcome of kidney transplantation.

Second, another discrepancy lies in the number of blood transfusions given. Although some centers (Morris, personal communication) have confirmed our finding that one blood transfusion protects graft survival, others have not (Opelz and Terasaki, 1978). This is another unexplained discrepancy. Preliminary findings from our group suggest that one blood transfusion is especially effective in the group of patients who received a one-DR-antigen-mismatched graft (see below). Because Opelz's patient material is racially more heterogeneous than the Dutch material, this observation might be relevant.

The mechanism by which blood transfusion protects graft survival is unknown. In all probability, this mechanism is different when many blood transfusions have been given as compared to the situation in which only one or a few were given. Many blood transfusions will induce cytotoxic HLA antibodies in many patients. Those who do not form cytotoxic HLA-A and -B antibodies are so-called "nonresponders." Graft survival in this group is known to be good. The term nonresponder is a misnomer, because these patients do form antibodies (anti-HLA-DR or other) that might be enhancing (Iwaki et al., 1978; Thompson et al., 1976). Those who have formed cytotoxic anti-HLA antibodies will receive kidneys from donors who lack the corresponding antigens. It is assumed but not proven that such recipients cannot easily form immunity against other HLA antigens, and thus incompatibility for these will not influence graft survival.

This selection phenomenon cannot play a role when only one blooc transfusion has been given because in such cases, no antibodies or only weak antibodies in only a few recipients are formed. Whether the improved graft survival is due to the induction of suppressor cells, broad reacting enhancing antibodies, or another mechanism is as yet unclear

In conclusion, almost everybody agrees that blood transfusion cal improve graft survival, but there is no agreement on the optimal numbe of blood transfusions to be given, the time interval between bloo.

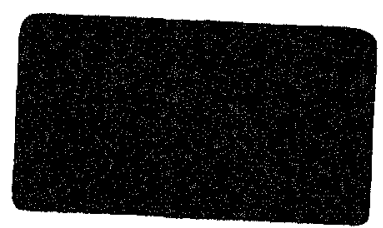


transfusion and transplantation, or even the way in which the blood should be prepared.

\section{HLA-DR Matching}

Almost from the beginning of clinical kidney allografting, evidence has been accumulating that indicated that a low or negative mixedlymphocyte culture (MLC) test was indicative for good transplant prognosis. This was in itself an important impetus to develop methods of typing the HLA-D determinants, which are the strongest stimulus in the MLC test (Transplantation Proceedings, 1977). The methods all used the basic MLC test or variants of it. However, because the MLC test is so time-consuming, it is suitable only for selection of living donorrecipient pairs.

Thus, a method was developed that would allow rapid identification of $H L A-D$-identical donor-recipient pairs and that could be applied to cadaveric donors. A systematic search for antibodies that could recognize the HLA-D determinants was begun. This effort was successful, and antibodies were identified that allowed the recognition of HLA-D antigens or determinants closely linked to them (Fig. 4) (van Rood et al., 1978). The main topic of the 7 th Histocompatibility Workshop was the recognition of these so-called "HLA-DR determinants" (Histocompatibility Testing 1977).

To assess the importance of $H L A-D R$ matching in kidney transplantation, $D R$ typing was performed on peripheral-blood cells of the recipient and frozen spleen cells from the corresponding kidney donor (Persijn et al., 1978). Figure 5A shows the influence of $D R$ matching alone and Fig. 5B the influence of $D R$ matching combined with (partial) matching for the HLA-A and -B antigens. Although the numbers are small and this is a retrospective study, the study strongly suggests that (1) even matching for one HLA-DR determinant can significantly reduce early graft loss (cf. Fig. 1); and (2) matching for HLA-DR combined with partial matching for the HLA-A and -B antigens might further improve prognosis; and (3) matching for both DR antigens appears to result in good graft survival as well, but here the numbers are too small for meaningful conclusions.

Other groups have done similar studies. A summary of the total of the published European data is presented in Table 1 (Ting and Morris, 1978; Martins-da-Silva et al., 1978; Albrechtsen et al., 1978). It is clear that although the number of $H L A-D R$-identical grafts is small, they give the highest percentage of functioning grafts in all series, and that the 


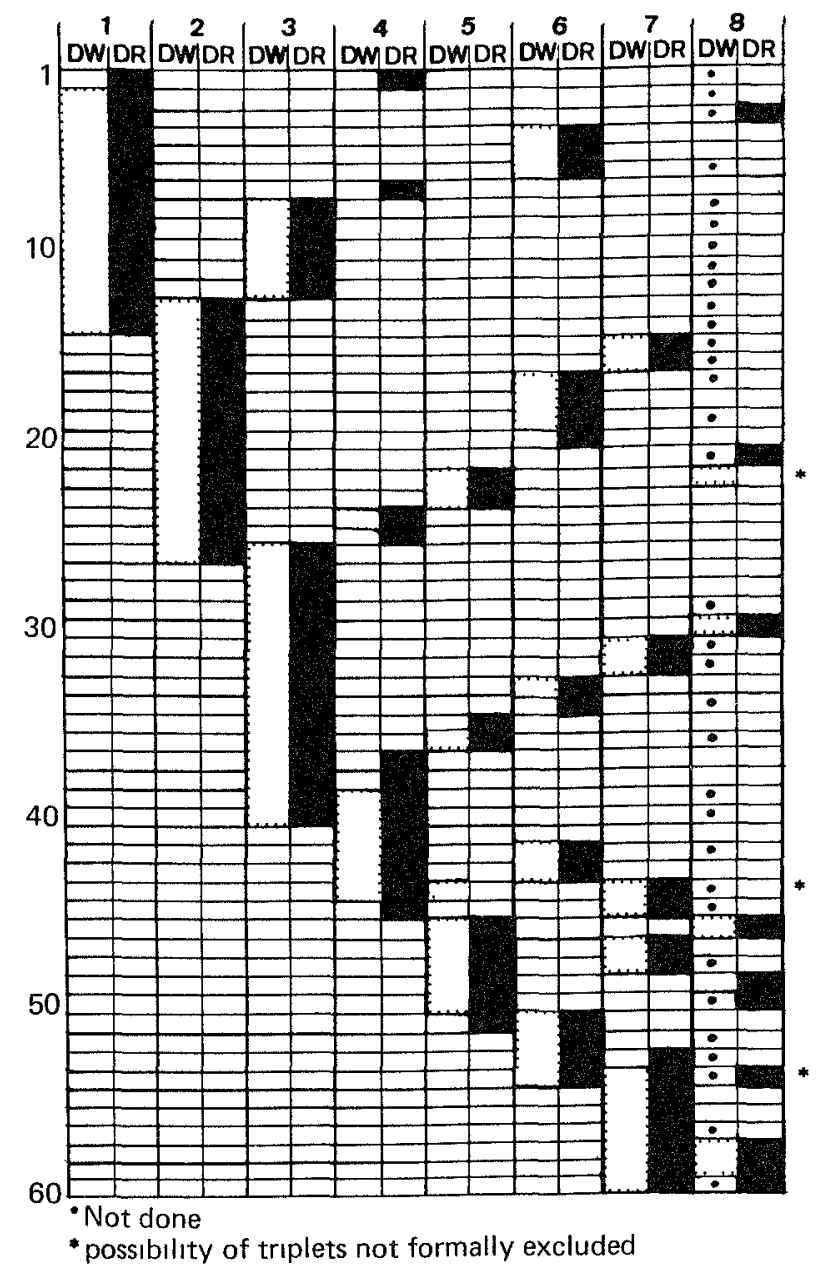

Figure 4 Results of testıng of lymphocytes of 60 unrelated donors by homozygous typing cells (HTC) and primed lymphocyte typing (PLT) recognizing the HLA D specificities HLA Dw1-8 Positive results are indicated by the stippled bars The same panel was tested by sera recognizing HLA DRw1-7 and HLA WIA 8 Positive results are indicated by the hatched bars Note the excellent agreement of the results obtained with cellular (HTC and PLT) and serological (HLA DR serology) technques fol determinants 1, 2, 3, and 7 The number of possible triplets is only one for HLA DR, suggesting that HLA DR determinants might be coded for by one locus

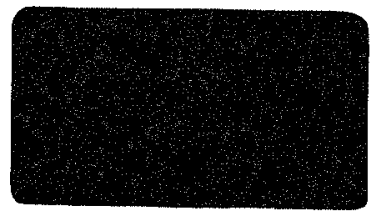


percentage of functioning grafts in the two-DR-antigens-mismatched group is the lowest. Problems arise with the one-DR-antigen-mismatched group because it is often unclear from publications of others whether these include potential incompatibilities or not (e.g., an HLA-DRwl/donor transplanted onto an HLA-DRwl/2 recipient). With this restriction, the available data show that in the majority of transplants performed in Europe, matching for two and also for one HLA-DR antigen improves graft survival significantly. The improvement by matching for two HLADR determinants was expected because earlier studies had shown that a low or negative MLC test between parent-child or unrelated donorrecipient pairs improved graft survival (Jeannet, 1970; Hamburger et al., 1971; Cochrum et al., 1973). Although not all $H L A-D$ - or -DR-identical combinations lead to a negative or low MLC test, the majority do

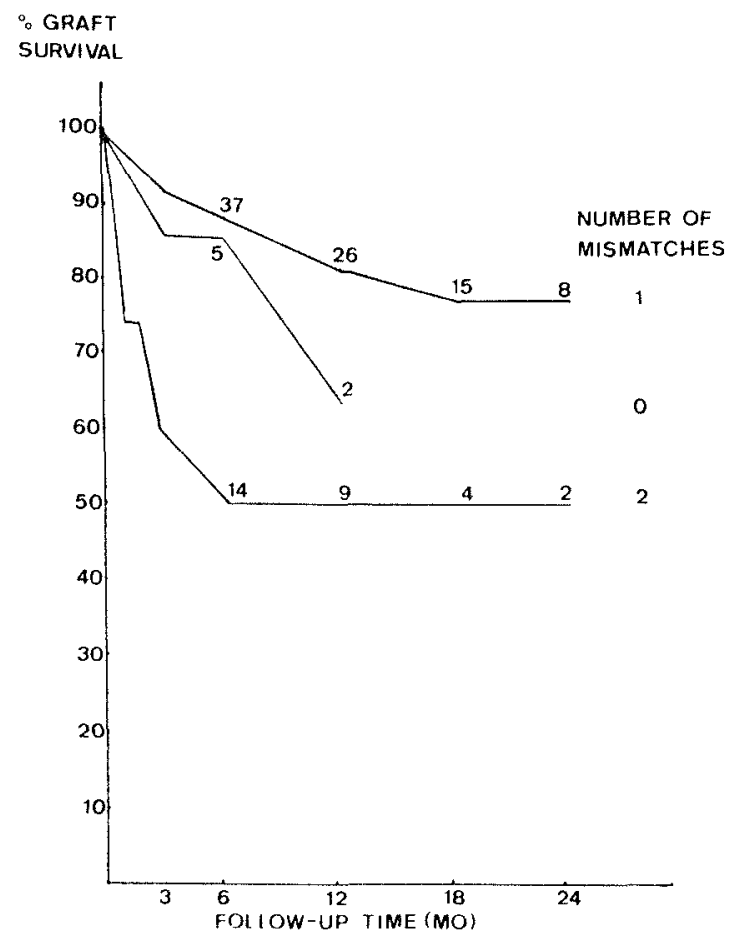

Figure 5A. Kidney-graft survival and matching for HLA-DR antigens alone. The top curve represents grafts with one mismatch at the $D R$ locus, the middle curve, $D R$-identical grafts, the bottom curve, grafts with two mismatches at the $D R$ locus. The figures above the curves are the numbers of grafts at risk. 


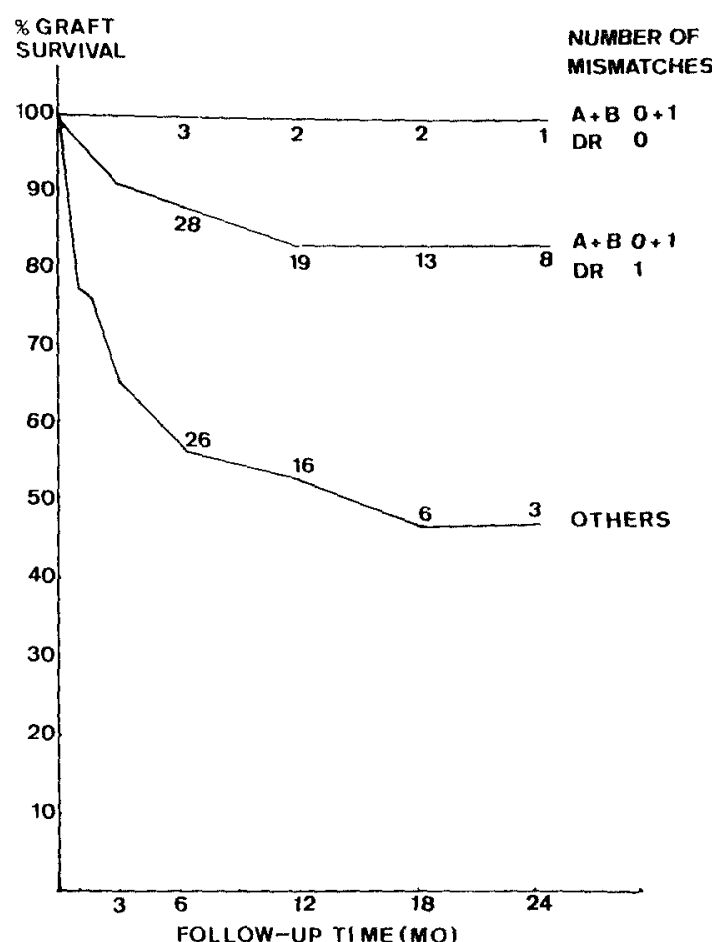

Figure 5B Kidney-graft survival and matching for HLA A, -B, and DR antrgens The top curve represents $D R$-identical grafts with one or fewer mismatches at the $A$ or $B$ locus, the middle curve, grafts with one or fewer mismatches at the $A$ or $B$ locus and one mismatch at $D R$, the bottom curve, other grafts From Persun et al (1978)

TABLE 1 DR Matching in Europe ${ }^{a}$

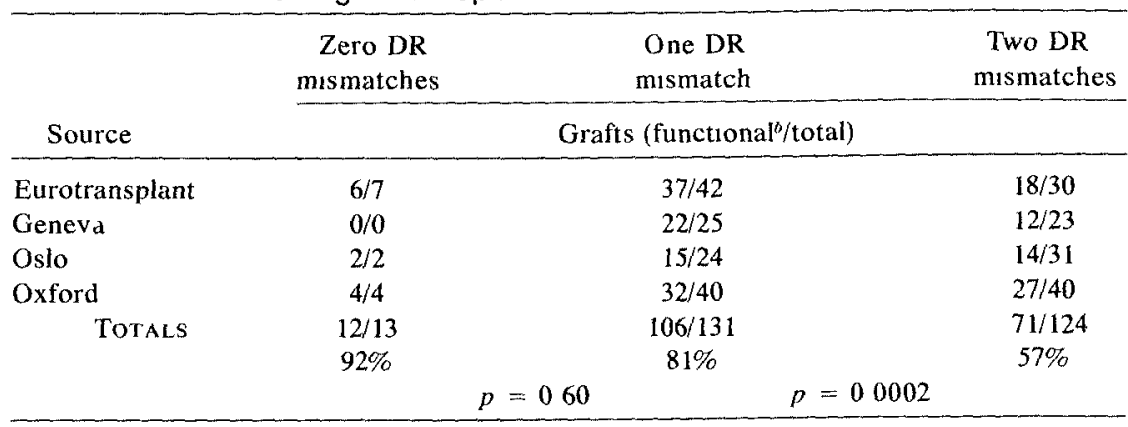

a For references, see van Rood et al (1979)

- At 6 months after transplantation

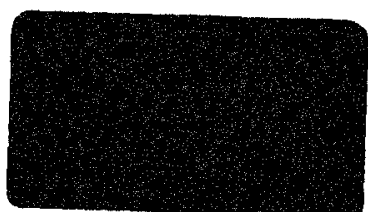


(Termijtelen et al., 1977), and this could explain the good results in the $H L A-D R$-identical group.

On the other hand, combinations that are mismatched for one HLADR determinant are always MLC-positive. Why is it then that grafts mismatched for one HLA-DR antigen do so well? From the point of immunogenetics, this is of course heresy: a difference of an antigen between donor and recipient has always been considered to be dominant over sharing an antigen, and the first question we have to answer is whether our observation that a one-DR-mismatched graft does so well is correct.

Corroboratory evidence was obtained from a study by van Hooff $e t$ al. (1974), who had already shown that matching between unrelated individuals for an HLA-A and $-\mathrm{B}$ antigen combination in strong linkage dysequilibrium with an HLA-DR determinant, such as the HLA$\mathrm{A} 1, \mathrm{~B} 8, \mathrm{DRw} 3$ combination, was associated with an improved graft survival. The percentage of graft survival exceeded that obtained for the overall survival in patients who were matched for two HLA-A and -B antigens that were not in linkage dysequilibrium. Thus, in this situation, donor and recipient were also matched, although indirectly, for one DR antigen (and mismatched for the other), and this was associated with better graft survival. There also exists corroborating evidence that oneDR-mismatched grafts do well in the parent-child data. They do much better than those differing by two DR antigens; in fact, in Holland they do as well as $H L A$-identical siblings (Persijn, unpublished observations). Others have made similar observations (Thompson et al., 1977a; Oliver et al., 1972; Fotino and Allen, 1972; Cochrum et al., 1973; Belzer et al., 1974; Dausset et al., 1974; Dausset and Hors, personal communications; Hors et al., 1974; Stenzel et al., 1974; Festenstein et al., 1976).

These observations reinforce our finding that matching for only one DR determinant can significantly improve graft survival. It is also clear that the data available are limited and in part retrospective and that prospective trials are indicated. This will be one of the main topics in the forthcoming 8th Histocompatibility Workshop. This is especially urgent because data from Los Angeles (Terasaki) and more recently from European studies have failed to show a significant improvement of graft survival in the one-DR-antigen-mismatched group. We cannot yet exclude, of course, the possibility that it is not $D R$ we should match for but another closely linked locus, e.g., HLA-D. Interracial transplants will be very useful in evaluating this (Troup et al., 1978).

It should be stressed that with the exception of two individuals, all the recipients in this study who received a kidney mismatched for one DR determinant had been transfused. Although this might be an important prerequisite, conflicting data exist on this point. Swedish workers found 
that graft survival in parent-child combinations was good only if the recipient had been transfused before transplantation (Brynger et al., 1977). The Dutch data are consistent with this, although a control group of nontransfused recipients is lacking. By contrast, Solheim et al. (1977) and Opelz and Terasakı (1978) did not find a graft-protectıng effect of blood transfusions in parent-child combinations, and furthermore Morris claims that the beneficial effect of $D R$ matching is most clear in the nontransfused group (Morris, personal communications).

In an attempt to clarify the mechanısm by which matching for one or two DR determinants overrides the effect of incompatibility for other antigens, we investigated whether these findings on $D R$ matching and graft survival had an in vitro correlate. Both MLC tests and cell-mediated lymphocytotoxicity (CML) tests (after in vitro priming) were studied. Lymphocytes were taken from patients 3-18 months after transplantation, and these were reacted with the splenocytes from their specific kıdney donor, which had been stored in liquid nitrogen. The lymphocytes of slightly more than half the patients who had functioning grafts had a negative CML test, while they were reactive with lymphocytes from random donors. We could actually show that the CML test changed from positive before transplantation to negative after transplantation (Fig. 6).

Our findings show striking similarity to observations of Thomas $e t$ al. (1977), who studied CML reactivity in parent-child combinations, and of Wonigeit and Pichlmayr (1977), who studied cadaveric-kidneytransplant recipients. The new data from these longitudinal studies presented here show that the increment of percentage kill against donor as measured in CML can be negative a few weeks and not many years after transplantation. In other words, a decreasing CML may be associated with good survival and an increasing CML with poor survival.

Although our prelıminary studies suggested that CML nonreactivity occurred most frequently in the one-DR-mismatched group, our recent, more extensive, data have falled to confirm this. In other words, CML nonreactivity and $D R$ matching appear not to be significantly associated.

In summary, the current picture emerges as follows.

1. Matching, for two and for one DR determinant improves graft survival to about $80 \%$ at 1 year. It should be stressed that almost three fourths of our patients were grafted with a kidney that carried zero or one $H L A-A$ or $-B$ mismatch only. Our data suggest that $D R$ matching reinforces but does not replace $H L A-A$ and $-B$ matching.

2. A fall in donor-specific CML develops in at least half the patients following transplantation. The origin of this phenomenon is under study 

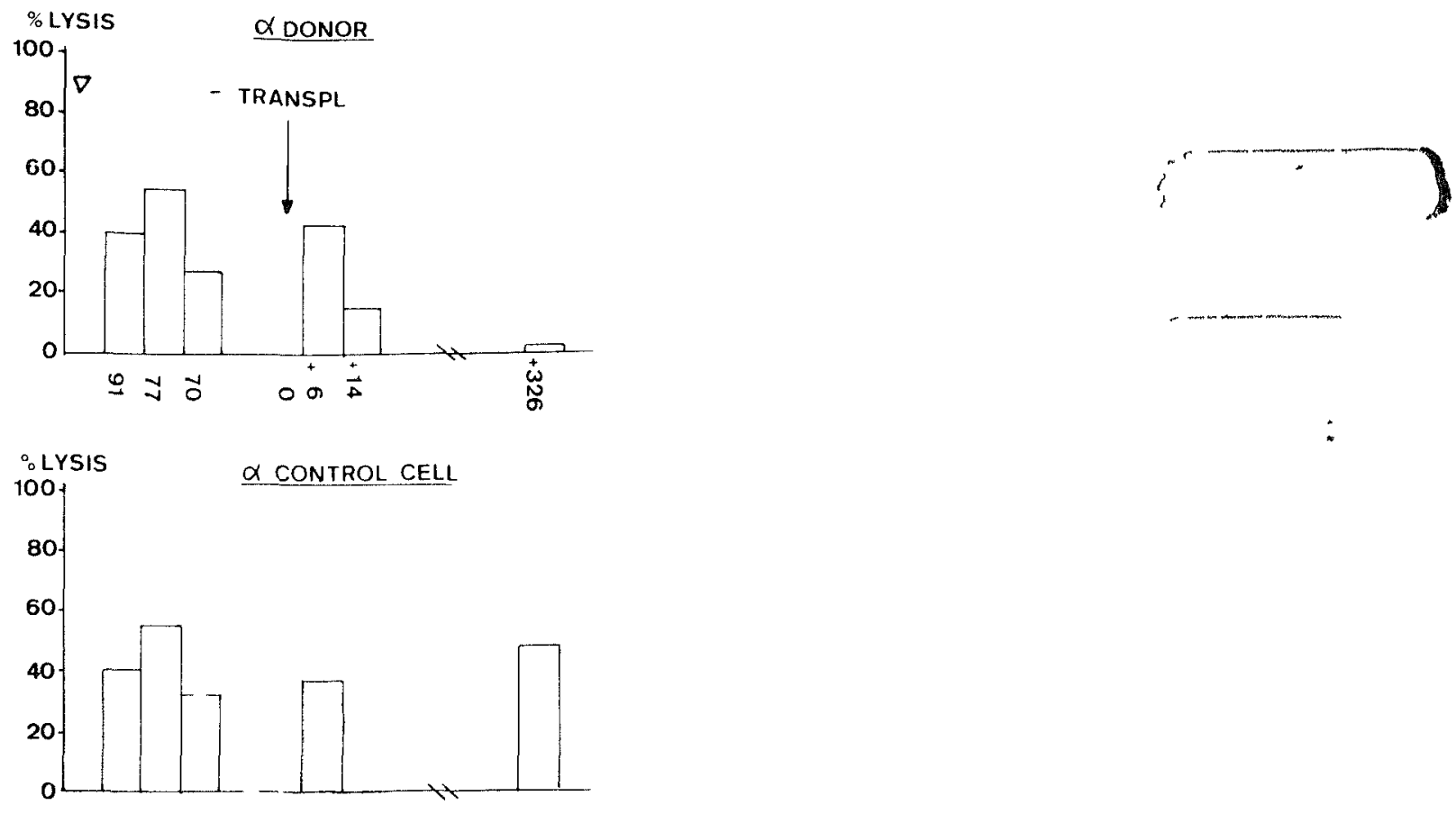

TIME IN DAYS

Figure 6 Longitudinal CML study after a planned blood transfusion $(\nabla)$ and kidney transplantation Top CML reactivity agarnst the specific kidney donor, bottom percentage lysis against a control cell The follow-up time in days is on the abscissa

\section{Incompatıbılity for Non-HLA Determınants}

Incompatibilities for determınants outsıde $H L A$ will influence graft survival as well. The first example of this was the deleterious effect of ABO-blood-group incompatibility on graft survival (Starzl et al, 1964). More recently, French workers have notıced that kıdneys transplanted in Lewis-blood-group-negative recipients have a poorer prognosis than Lewis-positive recipients, presumably because of incompatibility for the Lewis system (Oriol et al, 1978) This observation could explain why grafts from Caucasoid donors, who have a high frequency of Lewispositive individuals, do so poorly if transplanted in patients of negroid descent, who are often Lewis-negative

Very little attention has so far been pard to cell- or tissue-linespecific systems outside that of the HLA-DR antigens. However, Moraes and Stastny (1977) have identified a multiallelıc system that occurs on 
both endothelial cells and monocytes (Table 2). Paul et al. (1979) and Claas et al. (1979) have independently identified similar antibodies and have shown that these play in all probability an important role in rejection of both kidneys (Table 3) and bone-marrow grafts (Table 4). Little is yet known of the precise conditions under which these antibodies can be formed, but they can arise after repeated transfusions or kidney-graft rejection, or both. It is also uncertain whether the locus or loci coding for the determinants recognized by them lie in or near the $H L A$ complex, but Thompson et al. (1977b) have identified a polymorphic locus not linked to $H L A$ coding for determinants on monocytes, endothelial cells, and neutrophils. Now that the technical difficulties originally met in the recognition of the monocyte antigens have been solved and their clinical relevance has been established, it will not take long before a more complete description of the system will be possible.

Another point that has to be taken into account is that of MHC restriction, which is dealt with more fully in Chapter 3. In brief, MHC restriction implies that incompatibility for a non-MHC determinant will be recognized by the recipient only if donor and recipient share at least part of the HLA-A and -B determinants. To describe this, the term "dual recognition" was coined, by which is meant that both the non-MHC determinant and the self HLA-A or -B antigens have to be recognized on the target cell (Zinkernagel and Doherty, 1974; Shearer, 1974). The dualrecognition phenomenon was first described in the mouse, but it has also been shown to exist in man. The non-MHC determinants concern both intrinsic determinants such as $\mathrm{H}-\mathrm{Y}$ and extrinsic or acquired antigens such as those of choriomeningitis or influenza virus.

MHC-restricted immunity against $\mathrm{H}-\mathrm{Y}$ has been shown in the mouse

TABLE 2. Presence of $E$ Antigens in Endothelial (E) Cells and in Adherent Cells from Peripheral Blood ${ }^{a}$

\begin{tabular}{lccc}
\hline & \multicolumn{3}{c}{ Results of cytotoxicity tests } \\
\cline { 2 - 4 } Sera tested & E cells & $\begin{array}{l}\text { Adherent } \\
\text { monocytes }\end{array}$ & $\begin{array}{l}\text { Nonadherent } \\
\text { lymphocytes }\end{array}$ \\
\hline Experiment 1 & & & \\
G.B. & 50 & 60 & 10 \\
R.G. & 70 & 80 & 10 \\
W.W. & 60 & 40 & 10 \\
C.S. & 75 & 80 & 10 \\
E.W. & 90 & 70 & 10 \\
V.S. & 80 & 65 & 10 \\
\hline
\end{tabular}

a From Moraes and Stastny (1977).

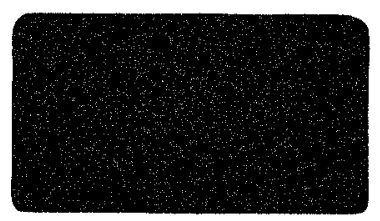


TABLE 3. Incidence of Circulating

Endothelial Antibodies (CEAb) in 97

Consecutive Allograft Recipients ${ }^{a}$

\begin{tabular}{|c|c|c|}
\hline \multirow[b]{2}{*}{ Clınical results } & \multicolumn{2}{|c|}{ CEAb } \\
\hline & Present & Absent \\
\hline $\begin{array}{l}\text { Irreversible vascular } \\
\text { rejection in less than } \\
50 \text { days }\end{array}$ & 7 & 5 \\
\hline $\begin{array}{l}\text { Graft survival for more } \\
\text { than } 50 \text { days }\end{array}$ & $2^{b}$ & 74 \\
\hline \multirow[t]{2}{*}{ Nonimmunological fallure } & 0 & 9 \\
\hline & 9 & 88 \\
\hline
\end{tabular}

skin-graft model to be a transplantation barrier of medium strength (von Boehmer et al., 1977; Hurme et al., 1978). In man, it has been shown that MHC-restricted anti-H-Y immunity can occur in vivo and in vitro using an indirect $\mathrm{CML}$ assay. It is of interest that so far $\mathrm{MHC}$ restriction has been found only for the HLA-A2 and $-B 7$ antigens, which belong to the most immunogenic antigens of the $H L A$ system. That this $H L A$ restricted anti-H-Y immunity is of clinical importance is not definitively proven, but suggestive evidence supporting this notion has been presented for both kidney and bone-marrow allografts (Table 5) (Storb et al., 1977; Goulmy et al., 1978). So far, such information is available only for $\mathrm{H}-\mathrm{Y}$ in man, but it is likely that this will be true for other non-MHC determinants as well, as has been discussed by one of us (Bradley and

TABLE 4. Correlation between the Presence of Antimonocyte Antibodies in the Serum and Rejection of the Bone-Marrow Graft ${ }^{2}$

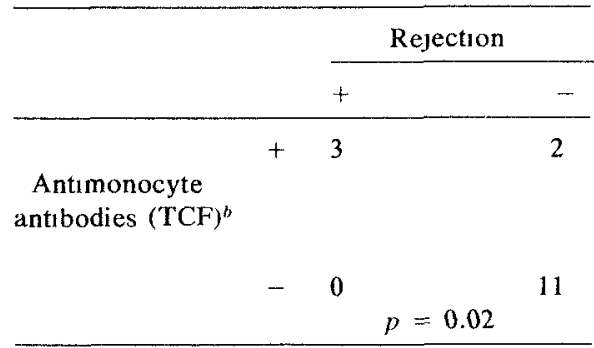

"From Claas et al. (1979)

D (TCF) Two-color fluorescence. 
TABLE 5 Two-year Actuarıal Cadaverıc-RenalGraft Survival in Eurotransplant Patients Sex and HLA-A2 Data for Male Donors and Female Recipients ${ }^{a}$

\begin{tabular}{|c|c|c|c|c|}
\hline \multicolumn{5}{|c|}{ Leukocyte antibody-positive group } \\
\hline Donor & A2-positive & A2 negatıve & \multirow[b]{2}{*}{$\mathbf{T}$} & \multirow[b]{2}{*}{$p$} \\
\hline & & & & \\
\hline \multirow{4}{*}{ Recipient } & A2 positive & A2-negatıve & \multirow{4}{*}{196} & \multirow{4}{*}{005} \\
\hline & $38 \%$ & $58 \%$ & & \\
\hline & & & & \\
\hline & $N=48^{b}$ & $N=50^{b}$ & & \\
\hline \multicolumn{5}{|c|}{ Leukocyte-antıbody-negative group } \\
\hline & $579 \%$ & $610 \%$ & \multirow{3}{*}{024} & \multirow{3}{*}{08} \\
\hline & & & & \\
\hline & $N=53^{b}$ & $N=53^{b}$ & & \\
\hline
\end{tabular}

Festenstein, 1978, Bradley, in prep ). An effect on graft survival of these non-MHC incompatibilities will be present only if donor and recipient share at least some of the HLA-A or -B determinants. In other words, if donor and recipient share none of the HLA-A or -B determinants, the effect of these determinants might be negligible. This could explain why grafts mismatched for three or four HLA-A and -B antigens sometımes do relatively well. These individuals, although mismatched for HLA-A and $-\mathrm{B}$, would suffer no adverse effect from non-HLA incompatıbilities If these show MHC restriction. In contrast, recipients of giafts wel, matched for HLA-A and -B would recognize most of the HLA-A- or -B restricted minor histocompatıbılity antigens.

All this concerns dual recognition in which a non-MHC and ar MHC determinant participate. There is, however, no reason to exclude the possibility that dual recognition could also exist between two differen classes of MHC determinants. A good case in point is the targets of the CML reaction in $H L A$, the so-called "CD determinants." Prelımınary studies indicate that these are closely associated with the HLA-A and $B$ determinants but not identical to them ( $F_{1} g$. 7). That this is indeed c case of $H L A-B$ restriction is suggested by the fact that not a singl positive reaction was found if neither Bw35 nor Bw53 was present. Wc assume that to recognize these $C D$ determinants, etther $B w 35$ or $B w 5$ must be present. The MHC-restricted non-HLA determinants have beeı named by Bradley the histocompatibility-dssociated membrane or (HAM minor antigens, the MHC-restricted HLA determinants, the HAM majo antıgens (Bradley and Festensteın, 1978).

We have discussed the role of dual recognition in connection witt

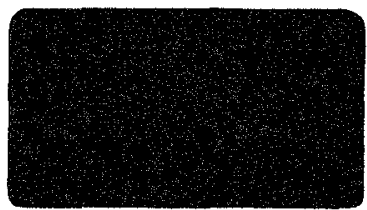




\begin{tabular}{|c|c|c|c|c|}
\hline \multirow[b]{2}{*}{ Panel } & \multicolumn{2}{|c|}{ HLA antıgens } & \multicolumn{2}{|c|}{ Cytotoxic effector cells } \\
\hline & Bw53 & Bw35 & Ant1-S1 & Ant1-S2 \\
\hline 1 & - & + & 43 & -2 \\
\hline 2 & - & + & 42 & -2 \\
\hline 3 & - & + & 46 & \\
\hline 4 & - & + & 46 & 0 \\
\hline 5 & - & + & 43 & -1 \\
\hline 6 & - & + & 43 & -2 \\
\hline 7 & - & + & 8 & 7 \\
\hline 8 & $\ldots$ & + & 57 & 2 \\
\hline 9 & - & + & 41 & 0 \\
\hline 10 & - & + & 34 & 2 \\
\hline 11 & - & + & 31 & 2 \\
\hline 12 & - & + & 41 & 1 \\
\hline 13 & - & + & 40 & 2 \\
\hline 14 & - & + & 43 & 1 \\
\hline 15 & - & + & 37 & 1 \\
\hline 16 & - & + & 39 & -2 \\
\hline 17 & - & + & 50 & 5 \\
\hline 18 & - & + & 48 & 0 \\
\hline 19 & - & + & 46 & 1 \\
\hline 20 & - & + & 20 & 35 \\
\hline 21 & - & + & 50 & 23 \\
\hline 22 & - & + & 1 & 19 \\
\hline 23 & - & + & 2 & 15 \\
\hline 24 & - & + & 7 & 28 \\
\hline 25 & - & + & 3 & 22 \\
\hline 26 & + & + & 27 & 3 \\
\hline 27 & + & + & 45 & 1 \\
\hline 28 & + & - & 24 & 2 \\
\hline 29 & + & - & 21 & 3 \\
\hline $30-70$ & - & & $\overrightarrow{0-9}$ & $0-5$ \\
\hline
\end{tabular}

Figure 7 Non-HLA-B CML killing. Cytotoxic effector cells (ant1-S1 and ant1-S2) were rassed in vitro between siblings of one family It was expected that these cells would react with Bw35-positive individuals It turned out that they did so only in part The donors carryıng the determinants recognized by antı-S1 and anti-S2 were always Bw35- and/or Bw53-positive, but the patterns of reactivity obtained with the cytotoxic cells were not identical with the serologically recognized Bw35 and Bw53 or any other HLA antigen. The lymphocytes of donors who were negatıve for the Bw35 and/or Bw53 antigens were not lysed.

the HAM minor and major antigens so far only in relation to the effector phase of the homograft response. That is the only part for which some limited evidence is available.

MHC-restricted immunity against non-HLA and HLA determinants does not occur spontaneously; in other words, it must be induced in 
vivo. Almost no systematic information is available on the conditions under which MHC-restricted immunity can arise, but it is assumed that this stimulus must be strong; i.e., it will occur only after many blood transfusions or graft rejection, or both. In practice, this means that MHC-restricted immunity will arise only when the recipient is repeatedly challenged with MHC and non-MHC incompatibilities, in which the MHC incompatibilities provide "help" for the recognition of the nonMHC incompatibilities.

\section{Discussion and Conclusions}

We certainly have not been able to give an all-encompassing answer to the question why some poorly matched kidneys survive so well, but we have made a preliminary inventorying of the different factors other than $H L A-A$ and $-B$ matching that (might) influence graft survival.

In our opinion, blood transfusion is one of the prime variables. Ever after a single pretransplant blood transfusion, the homograft reactior seems to be significantly weakened. The mechanism by which this occur is unclear, but could be due to the induction of an (aspecific?) suppresso cell (Thomas et al., 1977) or to the activation of cell clones that art capable of forming enhancing antibodies, or to both. On first sight, i might seem improbable that a single blood transfusion would be capable of inducing antibodies that would be able to enhance the survival o kidney grafts from almost any donor. Immunization against the deter minants of a single locus, e.g., $H L A-D R$, is incompatible with the induction of such broad-reactive enhancing antibodies (van Rood et al. 1979). However, if we take the MLC inhibition test as an in vitre analogue of in vivo enhancement, then a possible explanation offers itsel (Albert, personal communication; Bach, personal communication). Jon ker and van Rood (1978) and Albrechtsen et al. (1977) have shown tha not only anti-DR but also anti-HLA-A and -B antibodies can inhibit th MLC reaction. The question then becomes what the chance is that blood-transfusion donor will differ for one of the HLA-A, - B, - C, or -DI antigens with the recipient, while sharing it with the kidney donol Assuming that cross-reacting antigens can be counted as one, then it ca be calculated that in about $75 \%$ of the recipients of one blood transfusior the blood-transfusion donor will share a cross-reacting HLA-A, -B, or DR antigen with the kidney donor, while this antigen is absent in th recipient. This percentage of "enhanced" grafts can be added to th $20-30 \%$ of the grafts that do well even if no blood transfusion is give and would then result in the high percentage of well-functioning graft we have indeed found. This hypothesis is open to experimental proo

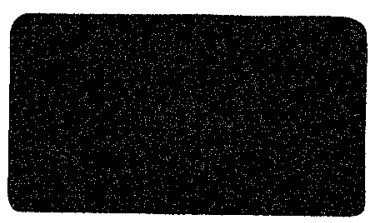


because one would expect that such antibodies would be detectable. We have not been able to demonstrate their presence with the complementdependent cytotoxicity test, but because more sensitive test systems have not yet been tried, their existence cannot be formally excluded.

If only one blood transfusion is given, we assume, but again have no hard data to evidence, that immunization against MHC-dependent or independent non-HLA antigens will not frequently occur. There are as yet insufficient data to assess the importance of (partial) matching for $H L A-D R$ in the nontransfused patient or after only one blood transfusion.

If, on the other hand, many blood transfusions have been given before transplantation, immunity against HLA and non-HLA determinants will often ensue, and depending on the match of donor and recipient, this will influence graft survival. In our patient material, partial matching for $H L A-D R$ improves graft survival significantly in this group of patients. CML nonreactivity can develop in a period of weeks posttransplantation independently of the $D R$ match. This CML nonreactivity might be due to the induction of suppressor cells or clonal inactivation or both.

Many of the still-existing discrepancies might disappear if full characterization of the antibodies formed after blood transfusion were carried out routinely. This can be quite difficult and is certainly not possible if only a standard complement-dependent cytotoxicity test is used. It is depressing to come to the conclusion that more than 20 years after it was shown that non-complement-binding antibodies can cause enhancement instead of graft rejection, almost all centers study their patients' sera only with complement-dependent cytotoxicity assays. A complete analysis of the methods that should be used to detect antibodies in the sera of transplant recipients and to determine their specificity has yet to be made. Such an analysis will, apart from the technical problems, also be hindered by our incomplete knowledge of the immunogenetics of the $H L A$ and especially the non- $H L A$ systems. A beginning of the inventorying of the non-HLA systems that are relevant in kidney transplantation and the way they exert their influence has been made. It should be stressed that it is so far only a beginning.

Acknowledgments. The authors would like to thank Professor John S. Thompson for his critical reading. This research was in part supported by the Dutch Organization for Health Research (TNO) and the Dutch Foundation for Medical Research (FUNGO), which is subsidized by the Dutch Foundation for the Advancement of Pure Research (ZWO); the J.A. Cohen Institute for Radiopathology and Radiation Protection (IRS); and the Dutch Kidney Foundation. 


\section{References}

Albrechtsen, D , Solheim, B G , and Thorsby, E , 1977, Antıserum inhibition of the mixed lymphocyte culture (MLC) interaction Inhıbitory effect of antibodies reactive with HLA D associated determinants, Cell Immunol 25:258

Albrechtsen, D, Flatmark, A , Jervell, J , Solheim, G, and Thorsby, E , 1978, HLA DR antigen matching in cadaver renal transplantation, Lancet 1:825

Belzer, F O , Perkıns, H A , Fortmann, J L , Kountz, S L, Salvaterro, O, Cochrum, K C , and Payne, R, 1974, Is HL A typing of clinical significance in cadaver renal transplantation?, Lancet 1:774

Bradley, B A , and Festenstein, H , 1978, Cellular typing, Br Med Bull 34:223

Brynger, H , Frisk, B , Ahlmen, J , Blohme, I , and Sandberg, L , 1977 Blood transfiusion and primary graft survival in male recipients, Scand J Urol Nephrol Suppl 42:76

Claas, F H J , van Rood, J J , Warren, R P , Weiden, P L , Su , P J , and Storb, R , 1979, The detection of non-HLA antibodies and their possible role in bone marrow graft rejection, Transplant Proc 11:423

Cochrum, K, Perkins, H A, Payne, R O, Kountz, S, and Belzer, F, 1973, The correlation of MLC with graft survival, Transplant Proc 5:391

Dausset, J, Hors, J, Busson, M , Festensteın, H, Oliver, R T D, Parı, A M I , and Sachs, J A , 1974, A joint analysis performed by France-Transplant and the London Transplant group, $N$ Engl J Med 290:979

Diepenhorst, P, Sprokholt, R , and Prins, H K , 1972, Removal of leukocytes from whole blood and erythrocyte suspensions by filtration through cotton-wool I Filtration technique, Vox Sang 23:308

Festenstein, H , Sachs, J A , and Pans, A M I , 1976, Influence of HLA matching and blood transfusion on outcome of 502 London Transplant group renal gratt recipients, Lancet 1:157

Fotino, M, and Allen, F H , 1972, A shared HL-A haplotype seems to make a cadaver donor satısfactory for kıdney transplantatıon, Vox Sang 22:309

Goulmy, E , Bradley, B A , Lansbergen, Q, and van Rood, J J , 1978, The importance of H Y incompatibility in human organ transplantation, Transplantation 25:315

Hamburger, J , Crosner, J , Descamps, B , and Rowmska, D , 1971, The value of present methods used for the selection of organ donors, Transplant Proc 3:260

Histocompatibility Testıng 1977 (W F Bodmer et al eds), 1978, Munksgadrd, Copenhag en

Hors, J , Busson, M , and Dausset, J , 1974, Role des incompatibilites HL-A et de la pre immunisation en transplantation renale, in Proceedings of the 5th International Course on Transplantation, Lyon, 1973 (J P Revillard, ed), pp 19-30, Simep Editions, Villeurbanne

Hurme, M , Hetherington, C M , Chandler, P R, and Simpson, E , 1978, Cytotoxic T cell responses to H Y Mapping of the $I t$ genes, $J$ Exp Med 147:758

Iwakı, Y , Terasakı, P I , Park, M S , and Bıllıng, R , 1978, Enhancement of human kıdney allografts by cold B-lymphocyte cytotoxins, Lancet 1:1228

Jeannet, M , 1970, Histocompatıbility testıng using leukocyte typıng and mixed lymphocyte culture in kıdney transplants, Hel Med Acta 35:168

Jonker, M, and van Rood, J J , 1978, Can ant HLA-A and B antigens inhibit the MLC test?, Tissue Antigens 11:251

Martins-da Silva, B , Vassallı, P, and Jeannet, M , 1978, Matching renal grafts, Lancet 1:1047 (letter to the editor)

Moraes, J R , and Stastny, P, 1977, A new antıgen system expressed in human endothelial cells, J Clin Ini est 60:449

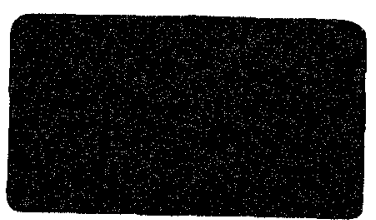


Morrıs, P J , Bishop, M , Fellows, G, Ledıngham, J G , Ting, A , Olıver, D , Cullen, P , French, M , Smith, J C , and Willams, K, 1978, Results from a new renal transplantation unit, Lancet 2:1353

Oliver, R T D, Sachs, J A , Festenstein, H , Pegrum, G D , and Moorhead, J F, 1972, Influence of HL-A matching antıgenic strength and immune responsiveness on the outcome of 349 cadaver renal grafts, Lancet 2:381

Opelz, G , and Terasakı, P I , 1978, Improvement of kıdney-graft survival with increased numbers of blood transfusions, $N$ Engl $J$ Med 299:799

Opelz, G, Sengar, D P, Mickey, M R , and Terasakı, P I , 1973, Eftect of blood transfusions on subsequent kıdney transplants, Transplant Proc 5:253

Onol, R , Cartron, J , Yvart, J , Bedrossian, J , Duboust, A , Bariety, J , Gluckman, J C , and Gagnadoux, M F , 1978, The Lewis system New histocompatibility antigens in renal transplantation, Lancet 1:574

Paul, L C, van Es, L A, van Leeuwen, A, van Rood, J J , de Graeff, J , and Brutel de la Riviere, G, 1979, Antıbodies directed against antigens on the endothelium of peritubular capillanes in patients rejecting renal allografts, Transplantation 27:175

Persijn, G G , van Hooff, J P , Kalff, M W , Lansbergen, Q, and van Rood, J J , 1977, Effect of blood transfusion and HLA matching on rend transplantation in the Netherlands, Transplant Proc 9:503

Persıjn, G G, Gabb, B W, van Leeuwen, A, Nagtegaal, A, Hoogeboom, J, and van Rood, J J , 1978, Matching for HLA antigens of A, B and DR loci in renal transplantation by Eurotransplant, Lancet 1: 1278

Persijn, G G , Cohen, B, and van Rood, J J , 1979, Eurotransplant Improved graft survival through HLA A, B and -DR matching and prospective blood transfusion policy, Dialysıs Transplant 8:493

Shearer, G M , 1974, Cell medidted cytotoxicity to trinitrophenyl modified syngenerc lymphocytes, Eur $J$ Immunol 4:527

Solheim, B , Flatmark, A , Jervell, J , and Arnesen, E , 1977, Influence of blood transfu sions on kidney transplant and uremic patient survival, Scand $J$ Urol Nephrol Suppl 42:65

Starzl, T E , Marchioro, T L, Hermann, G, Brittaın, R S , and Waddell, W R, 1964, Renal homografts in patıents with major donor-recipient blood group incompatibilities, Surgery 55:195

Stenzel, K H , Shitsell, J C , Cheigh, J S, Riggı, R R , Stubenborg, W T , Sullıvan, J F, Rubin, A L , and Fotıno, M , 1974, Effects of HL A matching and immune responsiveness on cadaver kidney graft survival, Transplant Proc 6:89

Stıller, C R , Sinclaır, N R , Sheppard, R R, Lockwood, B L, Ulan, R A, Sharpe, J A , and Hayman, P, 1978, Beneficial effect of operation day blood transfusions on human renal allograft survival, Lancet 1:169

Storb, R, Prentice, R L, and Thomas, E D , 1977, Treatment of aplastic anemid by marrow transplantation from HLA identical siblings Prognostic factors associated with graft versus host disease and survival, $J$ Clin Invest 59:625

Termitelen, A, Bradley, B A, and van Rood, J J , 1977, The influence of HLA A and B associated gene products on typing for HLA D by the HTC and PLT methods, Tissue Antigens 10:161

Thomas, J , Thomas, F, and Lee, H M , 1977, Why do HLA-nonidentical renal allografts survive 10 years or more', Transplant Proc 9:85

Thompson, J S , Jackson, D , Greacel, N A , Parmely, M J , and Severson, C D , 1976, Antıleukocyte antibody in postpartum and renal transplant subjects A comparison of capillar y agglutınation and lymphocytotoxicity reactions, Transplantation 21:85

Thompson, J S , Corry, R J , Lawton, R L , Bonney, W W , and Kaloyanides, G J , 1977d, 


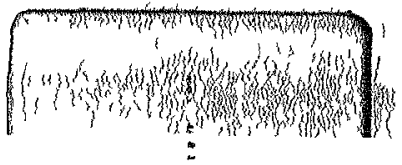

Effect of prospective HLA-haplotype matching on renal transplantation, Transplant Proc 9:205

Thompson, J S , Severson, C D , Greazel, N A, and Ferrone, S, 1977b, Detection of HLA (Ia) and non-HLA specificities by "B cell" antisera, Transplant Proc 9:597

Ting, A , and Morris, P J , 1978, Matching for B-cell antıgens of the HLA-DR series in cadaver renal transplantation, Lancet 1:575

Transplantation Proceedings, 1977, Vol 9

Troup, G M , Jameson, J , Thomsen, M , Svejgaard, A , and Walford, R L , 1978, Studies of HLA alloantigens of the Navajo Indians of North America I Variance of association between HLA-DRW (WIA) and HLA-DW specificites, Tissue Antrgens 12:44

van Es, A A , Marquet, R L , van Rood, J J , Kalff, M W, and Balner, H , 1977, Blood transfusions induce prolonged kıdney allograft survival in rhesus monkeys, Lancet 1:506

van Hooff, J P , Hendriks, G F J , Schippers, H M A, and van Rood, J J , 1974, The influence of possible HL-A haploidentity on renal graft survival in Eurotransplant, Lancet 1:1130

van Hooff, J P, Kalff, M W, van Poelgeest, A E, Persın, G G , and van Rood, J J , 1976, Blood transfusions and kidney transplantation, Transplantation 22:306

van Rood, J J , 1967, A proposal for international cooperation in organ transplantation Eurotransplant, in Histocompatibility Testing 1967 (E S Curtonı, P L Mattuz, and R M Tosi, eds ), pp 451-458, Munksgaard, Copenhagen

van Rood, J J , van Leeuwen, A , and Bruning, J W , 1967, The relevance of leucocyte antigens for allogeme renal transplantation, $J$ Clin Pathol Suppl 20:504

van Rood, J J , van Leeuwen, A , Termutelen, A , and Bradley, B A , 1978, HLA-D rally won by serology, in Histocompatibilty Testing 1977 (W F Bodmer, J R Batchelor, J G Bodmer, H Festensteın, and P J Morns, eds ), p 403, Munksgaard, Copenhagen

van Rood, J J , Persijn, G G , van Leeuwen, A , Goulmy, E, and Gabb, B W, 1979, A new strategy to improve kidney graft survival The induction of CML non responsive ness, Transplant Proc 11:736

von Boehmer, H, Fathman, C G , and Haas, W , 1977, H-2 gene complementation in cytotoxic $T$ cell responses of female aganst male cells, Eur $J$ Immunol 7:443

Wonigeit, K, and Pichlmayr, R, 1977, Specific defect in the capability to generate cytotoxic effector cells in vitro after organ transplantation in man, Dialysis Transplant 6:58

- Zinkernagel, R M , and Doherty, P C , 1974, Restriction of in vitro T cell-mediated cytotoxicity in lymphocytic chonomeningitıs within a syngenerc or semallogeneic system, Nature (London) 248:701 